\title{
BM] open Epidemiology of syphilis-related hospitalisations in Spain between 1997 and 2006: a retrospective study
}

\author{
Laura García-García, M Carmen Ariza-Megía, Alba González-Escalada, \\ Alejandro Álvaro-Meca, Ángel Gil-deMiguel, Ruth Gil-Prieto
}

To cite: García-García L, Ariza-Megía MC,

González-Escalada A, et al.

Epidemiology of

syphilis-related

hospitalisations in Spain between 1997 and 2006:

a retrospective study. BMJ

Open 2011;1:e000270.

doi:10.1136/

bmjopen-2011-000270

- Prepublication history for this paper is available online. To view these files please visit the journal online (http:// bmjopen.bmj.com).

Received 28 July 2011 Accepted 29 September 2011

This final article is available for use under the terms of the Creative Commons Attribution Non-Commercial 2.0 Licence; see http://bmjopen.bmj.com
Department of Preventive Medicine and Public Health and Medical Immunology and Microbiology, Rey Juan Carlos University, Madrid, Spain

Correspondence to Dr Laura García García; laura.garcia.garcia@urjc.es

\section{ABSTRACT \\ Objective: In order to illustrate the important public health impact of syphilis, which is a preventable infection, the epidemiology of syphilis-related hospitalisations in Spain was studied over a 10-year period.}

Methods: A retrospective study was conducted using the National Epidemiological Surveillance System for Hospital Data (Minimum Data Set). All hospitalisations due to syphilis infection in any diagnostic position (ICD9-CM 090-097) between 1997 and 2006 were analysed, according to the Spanish version of the International Classification of Diseases, ninth revision (ICD-9-CM).

Results: There were 9556 hospitalisations associated with syphilis in Spain. The hospitalisation rate was 2.33 per 100000 population, the mortality rate was 0.07 per 100000 population and the lethality was $3.17 \%$. The hospitalisation rate increased significantly after 2000 and was higher in men.

Conclusion: Syphilis remains a major public health problem because of both potential complications and its close association with HIV infection. It is necessary to promote early diagnosis, ensure treatment in patients with syphilis and emphasise health promotion and prevention programmes.

\section{INTRODUCTION}

Syphilis is a sexually transmitted infection (STI) of considerable public health importance due to both its global reach and its associated complications and sequelae. ${ }^{12}$

A late syphilis diagnosis can lead to complications such as bone, cardiovascular and neurological lesions; in women, it can cause pregnancy loss (abortion and stillbirth), premature delivery and maternal transmission to the fetus, resulting in congenital syphilis or death. ${ }^{1-3}$

The WHO estimates that more than half a million children are born with congenital syphilis in the world every year ${ }^{4}$ from infected pregnant women. A total of $25 \%$ of pregnancies to women infected with Treponema pallidum may end in stillbirth and $14 \%$ in

\section{ARTICLE SUMMARY}

Article focus

- To analyse the epidemiology of hospitalisations in patients with syphilis in Spain over a 10-year period (1997-2006)

- To compare the results with other notification systems existing in Spain.

- To show that current policies of control and prevention of syphilis infections in Spain can be improved.

Key messages

- Syphilis is a common infection in Spain and has increased during the last decade.

- Promoting early diagnosis in both men and women, ensuring treatment in patients with syphilis and emphasising prevention health programmes should be essential goals in order to avoid pregnancy complications and congenital syphilis.

- Unification of surveillance systems would improve the knowledge of syphilis epidemiology and comparison between countries.

Strengths and limitations of this study

- This study provides accurate information on the burden of syphilis.

- Due to the subclinical course of syphilis in most cases, hospitalised individuals represent only a small percentage of infected patients.

- Unification of these monitoring systems for prevention would improve sexually transmitted infection notification systems and, in turn, would allow a better comparison between countries.

neonatal death, representing an overall perinatal mortality of about $40 \% .^{3}$

Moreover, syphilis is closely related to infection with HIV. Ulcers caused by syphilis can increase the susceptibility and transmissibility of HIV, thereby increasing the risk of co-infection. ${ }^{2}$

The WHO estimates that there are 340 million new cases of curable STIs annually among men and women aged $15-49$ years, ${ }^{3}$ mostly in developing countries, although there has been an increase in the developed 
world. Recent epidemiological studies in Europe, the USA and Australia have shown that the number of syphilis cases has been increasing. ${ }^{25-7}$ After reaching its lowest rate in the 1990s, the incidence of syphilis has again increased significantly since $2001 .^{5} 6$

Since 2000, epidemic outbreaks have been recorded throughout Europe, mainly due to changes in sexual behaviour and recreational drug use among men who have sexual relationships with other men (MSM). ${ }^{8}$ An increase in syphilis rates has also been seen in the USA, ${ }^{5}$ Asia $^{9}$ and Oceania. ${ }^{2}$ Similarly, the increased incidence rates of syphilis in Spain began in 2002. ${ }^{1}$ Since that year, several studies showing increases in Barcelona $^{10}$ and Madrid $^{11}$ have been published. In 2008, a total of 2545 cases of syphilis were reported to the System of Diseases of Obligatory Declaration (EDO) in Spain, ${ }^{1}$ continuing the trend of an increasing incidence of this STI. This increase is also associated with outbreaks of syphilis among MSM. The practice of risky sexual behaviour associated with antiretroviral treatment could contribute to the greater number of syphilis infections in the HIV-positive population. ${ }^{2}$

The purpose of this study was to describe syphilisrelated hospitalisations in Spain between 1997 and 2006, using a population-based assessment. This study aims to illustrate the important public health impact of syphilis, which is a preventable infection, and to compare these results with other notification systems existing in Spain.

\section{MATERIALS AND METHODS}

This retrospective study used the National Epidemiological Surveillance System for Hospital Data (Minimum Data Set, MDS), which includes data from $98 \%$ of public hospitals in Spain. It is estimated that the National Health System covers $99.5 \%$ of the Spanish population. ${ }^{12-14}$ This monitoring system uses the Spanish version of the International Classification of Diseases, ninth revision (ICD-9-CM).

We analysed all hospital admissions due to syphilis infection (ICD-9-CM 090-097) in any diagnostic position for a period of 10 years (from 1 January 1997 to 31 December 2006) in Spain. The MDS data included demographic information (age and gender) and clinical data, including primary and secondary diagnosis.

Although the MDS does not record microbiological confirmation, the normal procedure for syphilis diagnosis in public hospitals in Spain involves microbial confirmation by laboratory tests.

We compared the hospitalisation data from the MDS with the information provided by the Notifiable Disease System (EDO) and the mortality data with mortality rates obtained from the National Institute of Statistics (INE).

\section{Statistical methods}

We calculated the annual hospitalisation rate (per 100000 populations/year), average length of stay, mortality rates (per 100000 populations/year) and case death rates (\% of deaths among hospitalised patients with syphilis). Population data were obtained from the municipal census for the years 1997-2006 in Madrid and were adjusted to the population covered by hospitals included in the MDS. It is assumed that the age distribution of patients treated in public hospitals is the same as the age distribution in the general population.

To test for associations between continuous variables, we used either Pearson or Spearman correlations. The Student $t$ test and ANOVA were used for comparison of means when parametric criteria were reached; for nonparametric distributions, we used the U-Mann-Whitney and Kruskal-Wallis tests. Differences between proportions were evaluated by $\chi^{2}$ tests. We used the Bonferroni correction to adjust for statistical significance for multiple comparisons. We calculated 95\% CIs, and $\mathrm{p}$ values $<0.05$ were considered statistically significant throughout the analysis.

Statistical analysis of data was performed using SPSS for Windows, V.17.0.

\section{RESULTS}

During the study period, there were 9556 syphilis-related hospitalisations in Spain, 5988 in men and 3563 in women. A total of $29.1 \%$ of patients had syphilis as the primary diagnosis, and $56.7 \%$ had syphilis as a second diagnosis. When the diagnosis of syphilis was secondary, the most common primary diagnoses were HIV, pregnancy complications related to syphilis and cerebral infarction. The average age of patients was 47.55 years $(\mathrm{SD}=21.490)$, and the average length of stay was 14.32 days $(\mathrm{SD}=19.382)$. Length of stay was significantly higher for men than women (table 1).

The most frequent comorbidities were HIV (13.05\%), complications during pregnancy (syphilis during pregnancy) (3.12\%), respiratory disease (pneumonia) $(2.70 \%)$ and hepatitis C (2.48\%).

The hospitalisation rate during the study period was 2.33 per 100000 population (95\% CI 2.29 to 2.38 ). In men, the hospitalisation rate was significantly higher $(\mathrm{p}<0.05), 2.98$ per 100000 population $(95 \%$ CI 2.90 to 3.05 ), which was almost twice the rate in women of 1.71 per 100000 population (95\% CI 1.64 to 1.77 ) (table 1).

There were 3563 syphilis-related hospitalisations in women, and $13.81 \%$ (492) of these women had syphilis or syphilis disorders associated with pregnancy. Over half of these women $(53.25 \%, 262)$ had a diagnosis of syphilis in pregnancy, $27.03 \%$ (133) had premature rupture of membranes, $7.11 \%$ (35) had delivered prematurely and $5.08 \%$ (25) had a diagnosis of spontaneous abortion or risk of miscarriage.

The mortality rate was derived from the number of patients who died in the hospital due to syphilis infection. There were 303 deaths during the study period among hospitalised patients, representing a mortality rate of 0.07 per 100000 population (95\% CI 0.07 to 
Table 1 Hospitalisation, mortality and case-fatality rates in patients with syphilis in Spain, by age group and gender (1997-2006)

\begin{tabular}{|c|c|c|c|c|c|}
\hline & $\mathbf{N}$ & $\begin{array}{l}\text { Hospitalisation rate } \\
\text { (per } 100000)(95 \% \mathrm{Cl})\end{array}$ & $\begin{array}{l}\text { Mortality rate (per } \\
100000)(95 \% \mathrm{CI})\end{array}$ & $\begin{array}{l}\text { Case-fatality } \\
\text { rate }(\%)(95 \% \mathrm{CI})\end{array}$ & $\begin{array}{l}\text { Average length of } \\
\text { stay(days) (SD) }\end{array}$ \\
\hline $\begin{array}{l}\text { General analysis } \\
\text { Gender }\end{array}$ & 9556 & 2.33 (2.29 to 2.38$)$ & 0.07 (0.07 to 0.08$)$ & 3.17 (2.82 to 3.52$)$ & 14.32 (19.382) \\
\hline Men & 5988 & 2.98 (2.90 to 3.05$)$ & $0.11(0.10$ to 0.13$)$ & 3.84 (3.35 to 4.33$)$ & $15.90(21.129)$ \\
\hline Women & 3563 & $1.71(1.65 \text { to } 1.77)^{*}$ & $0.04(0.03 \text { to } 0.04)^{*}$ & $2.05(1.58 \text { to } 2.51)^{*}$ & $11.65(15.662)^{*}$ \\
\hline \multicolumn{6}{|l|}{ Age (years) } \\
\hline $0-4$ & 481 & 2.63 (2.40 to 2.87$)$ & $0.03(0.01$ to 0.06$)$ & $1.25(0.26$ to 2.24$)$ & 15.35 (17.230) \\
\hline $5-9$ & 55 & $0.28(0.21$ to 0.35$)$ & 0 & 0 & 4.35 (4.562) \\
\hline $10-14$ & 83 & $0.38(0.30$ to 0.47$)$ & $0.01(-0.00$ to 0.03$)$ & $3.61(-0.40$ to 7.63$)$ & $9.17(13.025)$ \\
\hline $15-19$ & 174 & 0.68 (0.58 to 0.78$)$ & $0.02(0.00$ to 0.04$)$ & $3.45(0.74$ to 6.16$)$ & $9.17(16.958)$ \\
\hline $20-24$ & 396 & $1.23(1.13$ to 1.38$)$ & 0.01 (0.00 to 0.02$)$ & 1.01 (0.03 to 1.99$)$ & $7.48(9.961)$ \\
\hline $25-29$ & 629 & 1.81 (1.67 to 1.95$)$ & $0.03(0.01$ to 0.05$)$ & 1.91 (0.84 to 2.98$)$ & $8.76(11.464)$ \\
\hline $30-34$ & 880 & 2.56 (2.39 to 2.73$)$ & $0.02(0.00$ to 0.03$)$ & $0.68(0.14$ to 1.23$)$ & 11.07 (13.253) \\
\hline $35-39$ & 909 & 2.77 (2.59 to 2.95$)$ & $0.03(0.01$ to 0.05$)$ & $1.21(0.50$ to 1.92$)$ & $12.34(17.866)$ \\
\hline $40-44$ & 826 & $2.76(2.57$ to 2.95$)$ & $0.08(0.05$ to 0.11$)$ & $2.91(1.76$ to 4.05$)$ & $15.26(16.674)$ \\
\hline $45-49$ & 736 & 2.77 (2.57 to 2.97$)$ & $0.08(0.05$ to 0.12$)$ & 2.99 (1.76 to 4.22$)$ & $17.90(37.925)$ \\
\hline $50-54$ & 699 & 2.88 (2.67 to 3.09$)$ & $0.08(0.05$ to 0.12$)$ & 2.86 (1.63 to 4.10$)$ & $16.05(15.359)$ \\
\hline $55-59$ & 675 & 3.10 (2.87 to 3.34$)$ & $0.1(0.06$ to 0.14$)$ & 3.11 (1.80 to 4.42$)$ & $16.96(17.836)$ \\
\hline $60-64$ & 590 & 2.98 (2.74 to 3.22$)$ & $0.13(0.08$ to 0.18$)$ & 4.41 (2.75 to 6.06$)$ & $17.26(24.346)$ \\
\hline $65-69$ & 597 & 2.99 (2.75 to 3.23$)$ & $0.1(0.05$ to 0.14$)$ & 3.18 (1.77 to 4.59$)$ & $16.55(15.360)$ \\
\hline $70-74$ & 614 & 3.38 (3.11 to 3.64$)$ & $0.16(0.10$ to 0.22$)$ & 4.72 (3.05 to 6.40$)$ & $17.88(22.855)$ \\
\hline $75-79$ & 608 & 4.33 (3.99 to 4.68$)$ & $0.29(0.20$ to 0.38$)$ & 6.74 (4.75 to 8.74$)$ & $14.82(14.268)$ \\
\hline $80-84$ & 405 & 4.47 (4.04 to 4.91$)$ & $0.36(0.24$ to 0.49$)$ & 8.14 (5.48 to 10.81$)$ & 14.32 (14.453) \\
\hline$\geq 85$ & 199 & $2.73(2.35$ to 3.11$) \dagger$ & $0.27(0.15$ to 0.39$) \dagger$ & $10.05(5.87$ to 14.23$) \dagger$ & $15.74(13.432) \dagger$ \\
\hline
\end{tabular}

$0.08)$ and a case-fatality rate of $3.17 \%(95 \%$ CI 2.82 to 3.52) (table 1). Among patients who died, 29 had a primary diagnosis of syphilis (9.6\%), and 24 had neurological damage caused by syphilis. We found HIV $(15.18 \%)$, pneumonia $(3.3 \%)$, stroke and cerebral haemorrhage (both 2.64\%) as primary diagnoses for other patients who died.

Men had a mortality rate of 0.11 per 100000 population (95\% CI 0.10 to 0.13 ) and a case-fatality rate of $3.84 \%(95 \%$ CI $3.35 \%$ to $4.33 \%)$, both of which were significantly higher $(\mathrm{p}<0.05$ for both $)$ than those in women, who had a mortality rate of 0.04 per 100000 population (95\% CI 0.03 to 0.04 ) and a case-fatality rate of $2.05 \%$ (95\% CI 1.58 to 2.51$)$.

Seventy-three of the women hospitalised with syphilis died, six with a diagnosis related to syphilis (syphilitic myelopathy, syphilitic general paresis, syphilitic myocarditis and syphilitic ruptured cerebral aneurysm); cause of death in the remainder was due to HIV, cerebral haemorrhage, sepsis or a variety of malignancies. One of the women diagnosed with syphilis during pregnancy also died.

A total of 298 cases of congenital syphilis, defined as syphilis in the newborn due to maternal-fetal transmission in utero, ${ }^{15}$ were recorded, with two deaths among them.

Figure 1 shows a statistically significant increase in both overall hospitalisation rates and hospitalisation rates by gender during the study period (all $\mathrm{p}<0.05$ ). Between 1997 and 2000, there was a decrease in hospitalisations, following the trend of the 1990s. After 2000, however, the hospitalisation rate started to increase,
Figure 1 Syphilis related hospitalisation rate by gender in Spain (1997-2006).

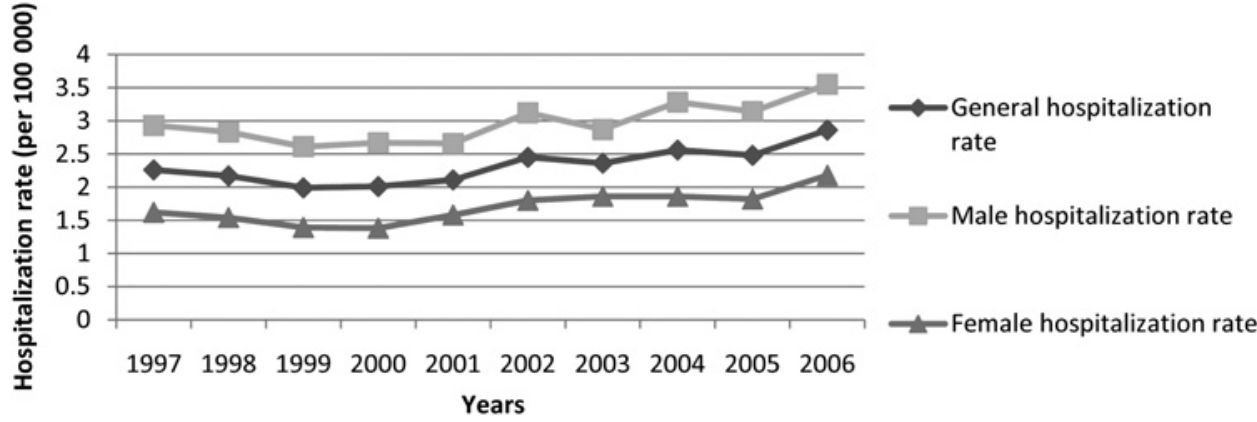


Figure 2 Hospitalisation, mortality and case-fatality rates related to syphilis by age group in Spain (1997-2006).

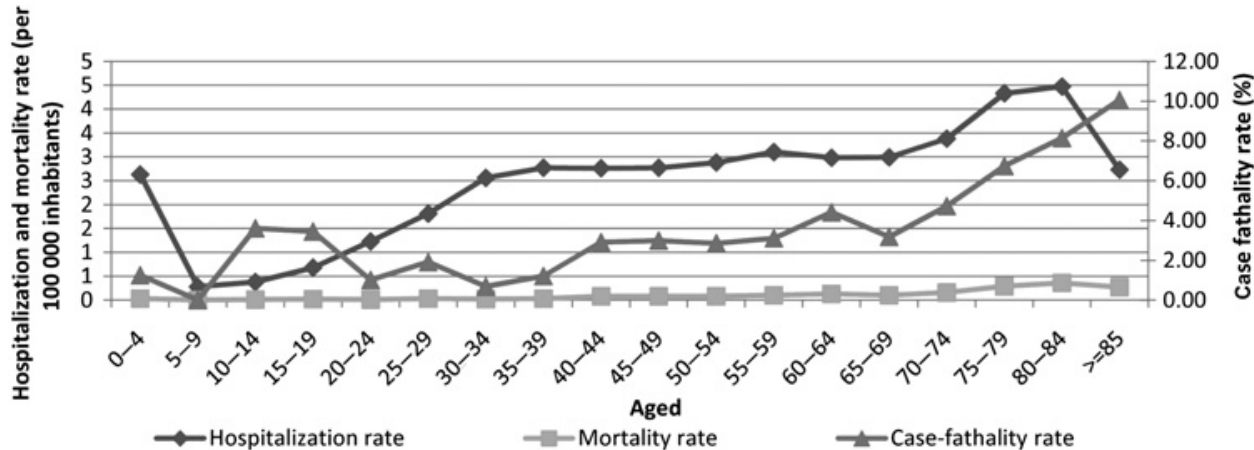

a trend that has persisted to the present. The highest hospitalisation rate was observed in 2006: 2.86 per 100000 population (95\% CI 2.70 to 3.01 ).

The mortality and case-fatality rates did not show statistically significant changes during the study period.

In stratified analyses by age group, there was a high hospitalisation rate in the age group $0-4$ years of 2.63 per 100000 population (95\% CI 2.40 to 2.87). There was also a significant increase in hospitalisation rates by age from 5 years. The highest rate of hospitalisation occurred in the age group of 80-84 years (4.47 per 100000 population (95\% CI 4.04-4.91)) (figure 2). The hospitalisation rate decreased in patients 85 years of age and older.

The mortality and case-fatality rates increased significantly with age $(p<0.05)$, reaching the maximum rate at age 80 years.

Figure 3 shows the distribution of hospitalisation rates by region. The autonomous communities that had the highest hospitalisation rates were Ceuta and Melilla, with 6.78 and 11.52 per 100000 population, respectively, and the lowest rates were found in Castilla La Mancha and the Basque Country, with 1.26 and 1.35 per 100000 population, respectively.

Figure 3 Syphilis related hospitalisation rate by region in Spain (1997-2006).

\section{DISCUSSION}

Syphilis infections are of mandatory notification in Spain through the EDO. All new cases are recorded on a weekly basis at both the primary care and hospital level. There are also sexually transmitted infection regional centres, where patients with sexually transmitted infections are treated and followed. Hospitalisations occur in the most severe cases, latent and tertiary syphilis or comorbidities. The aim of this study was to analyse the epidemiology of hospitalisations in patients with syphilis in Spain over a 10-year period (1997-2006) and compare our results with the existent data reported to the EDO and the mortality data obtained from the INE. Our results do not show the real incidence of syphilis infection, as primary and secondary infections are mainly treated in primary care centres. That is the reason why we do not talk about incidence, but about hospitalisation rates throughout the paper.

Our results show the same upward trend in hospitalisation rates as the data collected by the EDO (763 cases in 1996 and 1711 in 2006). ${ }^{1}{ }^{16}$ The syphilis-related hospitalisation rate in Spain increased significantly between 1997 and 2006, as demonstrated in previous studies. ${ }^{17}$ In the rest of Europe ${ }^{18-22}$ and in the USA, ${ }^{2324}$ 
the syphilis infection rate also started increasing in the year 2000 after years of steady decline.

By comparing the figures obtained in the present study with the total number of cases reported to the EDO, ${ }^{1}$ we can estimate that $42 \%$ of the syphilis infections need hospitalisation. Both hospitalisation rates and incident estimates obtained in this study are higher than those published for other European countries. ${ }^{19}$ Possible explanations for these figures could be different sexual behaviours and the increasing immigrant population since 2000 coming from different regions with higher syphilis incidences.

There were significant differences by gender, with higher hospitalisation rates among men, a finding compatible with data published in the USA, ${ }^{25}$ China $^{26}$ and various European countries ${ }^{27}$ that show increased cases in men and particularly in MSM. This could be due to the behavioural changes of this population group, with a decrease in the preventive measurements and the increase of risky sexual practices that favour the infection. ${ }^{28}$

We found a high rate of hospitalisation in children under the age of 5 years, which may be due to vertical transmission from mother to child that resulted in congenital syphilis, as the rate of hospitalisation in women also increased during the study period. Cases of congenital syphilis increased in Spain during the study period, with 298 new cases including two deaths. Pregnant women are tested twice for syphilis infection during the routine pregnancy controls in the National Health System in Spain, a first serology in the first antenatal consultation and a second one in the third trimester. Treatment is given to the woman and her partner when needed. If a woman is positive for infection, a second serology will be done during delivery, to both the mother and the newborn to check its serological status. ${ }^{3}{ }^{4}$ The increase of congenital syphilis during the study period reflects an increase in the primary and secondary syphilis cases among women in Spain. It could be due to the increasing immigrant population from countries where syphilis incidence is higher. These women can have a lower adherence to the health system and less access to prenatal consultation, and can be at a higher risk of syphilis and HIV transmission. Universal screening and treatment of women positive for syphilis offers immediate benefits both to the mother and in the location and treatment of potentially infected couples. It also prevents the transmission of syphilis and HIV and prevents the development of complications in newborns and in mothers and their partners. ${ }^{4}$

Therefore, improvement in the control and prevention of STI in pregnant women is necessary, as well as early treatment to prevent transmission of the disease. A recent French study showed that screening pregnant women in the first trimester of pregnancy improves diagnosis and prevents congenital syphilis cases. ${ }^{29}$

Hospitalisation rates increased in people older than 65 years, which may be due to other chronic or acute age-related pathologies, such as respiratory disease (pneumonia), cerebrovascular disease and stroke or cerebral haemorrhage. Furthermore, we found higher rates of hospitalisation among young adults. These findings are similar to data from several other countries: Germany, where the average age of syphilis cases was $20-40$ years $^{7}$; Ireland, where the average age was $20-44$ years $^{21}$; and the USA, where the average age was $35-39$ years. ${ }^{30}$

The mortality rate increased significantly with age and was highest after the age of 65 years. A high percentage of hospitalisations were due to complications associated with syphilis. When comparing our findings with the mortality rate data from the INE, we found a lower mortality rate in the INE data, from an annual 0.01 to 0.03 per 100,000 during the study period. This may be mainly due to the fact that hospital deaths may have been attributed to other diseases in these patients such as HIV, pneumonia and cerebrovascular diseases, which are common comorbidities with syphilis. ${ }^{4} 2131$

Despite the heterogeneity of monitoring systems, diagnosis and control of STIs throughout the world, there has been a global trend of an increase in syphilis in recent years. Due to the subclinical course of syphilis in most cases, hospitalised individuals represent only a small percentage of infected patients. However, by including in the present study syphilis listed in any diagnostic position in the MDS, we minimised this under-reporting due to limited information. A unification of these monitoring systems for prevention would improve STI notification systems and, in turn, would allow a better comparison between countries. Syphilis is a major public health problem because of the potential complications and its close association with HIV infection. Promoting early diagnosis in both men and women, ensuring treatment in patients with syphilis and emphasising prevention health programmes should be essential goals to avoid pregnancy complications and to reduce and prevent complications caused by congenital syphilis. ${ }^{4} 32$ These goals would also help decrease transmission among MSM.

Acknowledgements We would like to thank the General Sub-direction of the Institute for Health Information for providing the information on which this study is based.

Correction notice The "To cite: ..." information and running footer in this article have been updated with the correct volume number (volume 1).

Funding This research received no specific grant from any funding agency in the public, commercial or not-for-profit sectors.

\section{Competing interests None.}

Contributors LGG participated in the data analysis, statistics and draft writing. CAM contributed in the data analysis, statistics and draft writing. AGE collaborated in the study design and draft review. AAM collaborated in the database design, data extraction and draft writing. AGM participated in the study design and draft approval. RGP contributed in the study design, data analysis, statistics and draft review. All the authors have seen and approved the final version.

Provenance and peer review Not commissioned; externally peer reviewed.

Data sharing statement No additional data available. 


\section{REFERENCES}

1. Instituto de Salud Carlos III. Vigilancia Epidemiológica de las Infecciones de Transmisión Sexual, 1995-2008. http://www.isciii.es/ htdocs/pdf/its.pdf (accessed 15 Jul 2010).

2. Jin F, Prestage GP, Kippax SC. Syphilis epidemic among homosexually active men in Sydney. Med J Aust 2005;183:179-83.

3. World Health Organization. Global Strategy for Prevention and Control of Sexually Transmitted Infections 2006-2015. http://www. who.int/topics/sexually_transmitted_infections/en/ (accessed 12 Oct 2010).

4. World Health Organization. The Global Elimination of Congenital Syphilis: Rationale and Strategy for Action. http://www.who.int/ reproductivehealth/publications/rtis/9789241595858/en/index.html (accessed 15 Nov 2010).

5. Peterman TA, Furness BW. The resurgence of syphilis among men who have sex with men. Curr Opin Infect Dis 2007;20:54-9.

6. Peterman TA, Heffeldinger JD, Swint EB, et al. The changing epidemiology of syphilis. Sex Transm Dis 2005;32:S4-10.

7. Marcus U, Bremer V, Hamouda O. Syphilis surveillance and trends of the epidemic in Germany since the mid 90's. Euro Surveil 2004;9:11-14.

8. Fenton KA, Lowndes CM. Recent trends in the epidemiology of sexually transmitted infections in the European Union. Sex Transm Infect 2004;80:255-63.

9. Tucker JD, Chen XS, Peeling RW. Syphilis and social upheaval in China. N Engl J Med 2010;362:1658-61.

10. Vall-Mayans M, Casals M, Vives A, et al. Re-emergence of infectious syphilis among homosexual men and coinfection with human immunodeficiency virus in Barcelona, 2002-2003. Med Clin (Barc) 2006;126:94-6.

11. Cabello L, Arce A, Burgoa M, et al. ¿Resurge el viejo problema de la sífilis? Estudio en un área de Madrid. Gac Sanit 2004;18(Suppl 3):92. http://apps.elsevier.es/watermark/ctl_servlet?_f=10\& pident articulo $=13069235 \&$ pident $u$ suario $=0$ \&pcontactid $=$ \&pident_revista $=138 \&$ ty $=47 \&$ accion $=$ L\&origen $=$ elsevier $\&$ web $=$ www.elsevier.es\&lan =es\&fichero=138v18nSupl.3a13069235pdf001. pdf (accessed 13 Oct 2011).

12. Ministry of Health. International Classification of Diseases 9 Revision Clinical Modification. 2010. http://www.msps.es/ecieMaps2010/basic_search/cie9mc_basic_search.html (accessed 15 Nov 2010).

13. Instituto Nacional de la Salud. Subdirección general de coordinación Administrativa. Conjunto Mínimo Básico de Datos. Madrid: Hospitales del INSALUD 2001, 2002. http://www.ingesa.msc.es/ (accessed 15 Nov 2010).

14. Rivero Cuadrado A. El conjunto mínimo básico de datos en el SNS: inicios y desarrollo actual. Rev Fuentes Estadísticas 2000;49:18-19. http://www.ingesa.msc.es/estadEstudios/documPublica/pdf/CMBD2001.pdf (accessed 16 Nov 2010).
15. Global burden of Sexually Transmitted Diseases (excluding HIV) in the year 2000. WHO. http://www.who.int/healthinfo/statistics/ bod_sexuallytransmitteddiseasesotherthanHIVAIDS.pdf

16. National Institute of Statistics. Annual Bulletin of Notifiable Diseases Data from the Instituto de Salud Carlos III. http://www.isciii.es/jsps/ centros/epidemiologia/seriesTemporalesAnuales.jsp (accessed 17 Nov 2010).

17. González-López JJ, Guerrero ML, Lujan R, et al. Factors Determining serologic response to Treatment in Patients with syphilis. Clin Infect Dis 2009;49:1505-11.

18. Simms I, Fenton K, Ashton M. The Re-Emergence of syphilis in the United Kingdom: The New Epidemic phases. Sex Transm Dis 2005;32:220-6

19. World Health Organization. Data and Statistics in Europe (CISID) 2009. http://data.euro.who.int/CISID/ (accessed 11 Nov 2010).

20. Van de Laar M, van Veen M, Götz H, et al. Continued transmission of syphilis in Rotterdam, the Netherlands. Euro Surveil 2003;7:39.

21. Hopkins S, Lyons F, Coleman C, et al. Resurgence in infectious syphilis in Ireland. Sex Transm Dis 2004;31:317-21.

22. Cowan S. Syphilis in Denmark-Outbreak among MSM in Copenhagen, 2003-2004. Euro Surveil 2004;9:25-7.

23. Centers of Disease Control and Prevention. Primary and secondary syphilis: United States 2003-2004. MMWR Morb Mortal Wkly Rep 2006;55:269-73.

24. Klausner JD, Kent CK, Wong W, et al. The public health response to Epidemic syphilis, San Francisco, 1999-2004. Sex Transm Dis 2005;32:S11-18

25. Chen JL, Kodagoda D, Lawrence AM, et al. Rapid public health interventions in response to an outbreak of syphilis in Los Angeles. Sex Transm Dis 2002;29:277-84.

26. Ruan Y, Li D, Li X, et al. Relationship Between Syphilis and HIV infections among men who have sex with men in Beijing, China. Sex Transm Dis 2007;34:592-7.

27. Velicko I, Arneborn M, Blaxhult A. Syphilis epidemiology in Sweden: re-emergence since 2000 primary due to spread among men who have sex with men. Euro Surveil 2008;13(50):pii19063.

28. National Institute of Statistics. Survey of Health and Sexual Habits 2003. http://www.ine.es/prodyser/pubweb/saludyhs03/saludyhs03. htm (accessed 5 Sep 2011).

29. Nicolay N, Gallay A, Michel A, et al. Reported Cases of congenital syphilis in the French national hospital database. Euro Surveil 2008;13:19062.

30. Chesson H, Zaidi A, Aral S. Decreasing age disparities in incidence syphilis and gonorrhoea rates in the United States, 1981-2005. Sex Transm Dis 2008;35:393-7.

31. National Institute of Statistics. Deaths by Cause of Death. http://www. ine.es/jaxi/menu.do?type $=$ pcaxis \&path $=/ \mathrm{t} 15 / \mathrm{p} 417 \&$ file $=$ inebase $\& \mathrm{~L}=0$ (accessed 12 Nov 2010)

32. Simms I, Ward H. Congenital syphilis in the United Kingdom. Sex Transm Infect 2006;82:1. 